\title{
Multiple sulfur isotopes of carbonatites, a window into their formation conditions
}

\author{
A. BOUYON ${ }^{1,5}$, M. KLAUSEN ${ }^{2}$, J. MATA $^{3}, \mathrm{~S}$. \\ TAPPE $^{4}$, J. FARQUHAR ${ }^{5}$, P. CARTIGNY $^{1}$
}

${ }^{1}$ Institut de Physique du Globe de Paris

${ }^{2}$ University of Stellenbosch

${ }^{3}$ Universidade de Lisboa

${ }^{4}$ University of Johannesburg

${ }^{5}$ University of Maryland

Carbonatites are rare volcanic rocks whose carbon/oxygen isotope signatures point towards a mantle origin. However there is still debate on the role of processes such as partial melting or the recycling of sediments for their generation. Carbonatite quadruple sulfur isotope measurements should be useful for deciphering the imprints of Earth's earliest atmosphere and microbial cycling, two processes isotopically characterized by different slopes in a $\Delta^{33} \mathrm{~S}-\Delta^{36} \mathrm{~S}$ diagram, and thus help to better understand the origin of carbonatites, and the possiblity of sedimentary precursors, in greater detail.

We report here multiple sulfur data for a wide range of carbonatite samples: 4 continents, from today to $3 \mathrm{Ga}$, oceanic and continental settings. 80 measurements from 18 localities yielded sulfur in sulfides between 0 to $1 \mathrm{wt} \%$, with $\delta^{34} \mathrm{~S}$ ranging from $-20 \%$ to $+10 \%$. The record through time seems to correlate with the sedimentary record albeit with some delay. $\Delta^{33} \mathrm{~S}$ varies between -0.1 to $0.4 \%$. Most of the samples display unequivocal mass-dependent fractionation, characteristic of the sedimentary record. A few samples show mass-independent fractionation.

$\Delta^{33} \mathrm{~S}$ shows a temporal variation from near zero at $3 \mathrm{Ga}$ to positive values until $500 \mathrm{Ma}$ and then a broadening with both positive and negative values. This is interpreted to reflect the assimilation of surface derived sulfur in the source of carbonatites. The mixing with mantle sulfur narrows the amplitude of the variation and a crustal imprint could blur the signal as well. However coupled $\delta^{34} \mathrm{~S}-\Delta^{33} \mathrm{~S}$ point toward two different stages in the sulfur isotopic signature: a long recycling before $900 \mathrm{Ma}$ and a much shorter residence time, on the order of 300 Myrs, after. This could be linked with a preferential recycling of sulfides in the early time and a recycling of both sulfides and sulfates later on. 